\title{
The alignment between the ESP course materials and the English language used in the hotel setting in Vietnam
}

\author{
Vu Thi Hong $\operatorname{Van}^{1 *}$ \\ ${ }^{1}$ Ho Chi Minh City University of Education, Vietnam \\ *Corresponding author: vuthihongvandhsp@yahoo.com
}

\begin{abstract}
ARTICLE INFO
ABSTRACT

DOI: $10.46223 / \mathrm{HCMCOUJS.}$

soci.en.9.2.263.2019

Received: November $3^{\text {rd }}, 2019$

Revised: December $10^{\text {th }}, 2019$

Accepted: December $13^{\text {th }}, 2019$

Keywords:

authentic materials, ELF, ESP, tourism and hospitality

This article examines the alignment between the ESP course materials - English for hotel majored students - and the English language used in the hotel setting in Vietnam. English textbooks which were commonly used in the ESP courses for hospitality students were reviewed for the limits on the portion of the written materials in comparison with the English language used by the hotel staff in the real-life setting. Content analysis was adopted for analyzing the course materials, particularly the activities provided for students to practice listening and speaking skills. The findings reveal that the textbooks cover a wide range of activities for students to practice communicative skills. However, most activities were situated in environments that were unfamiliar to students and that might limit students' ability to meet guests' needs.
\end{abstract}

\section{Introduction}

Globalization has had a great worldwide on service industries with tourism and hospitality being two of the most affected sectors. The hotel industry has been identified as a key service sector providing hospitality services. This industry, as Sparks (1994) observed, is "very much a communicative encounter" (p. 39) and "customers evaluate the quality of service, at least in part, on the manner in which information is communicated" (p. 48). Consequently, comprehensible communication is a necessary skill for the hotel staff, and it is central to the success of the hotel industry. Within this industry, English is the most commonly used language for communication. and it has become the lingua franca of hotel staff and tourists and travelers worldwide.

With beautiful natural scenery and stunning heritage, Vietnam has become one country in Southeast Asia that is attracting a growing number of foreign visitors to the country every year for different purposes, and mainly for tourism. According to the Vietnam National Administration of Tourism (VNAT, 2019), in 2018 Vietnam received more than 15 million international arrivals. Of the foreign guests, there is a high number of visitors from Asia (more than 12 million) include China, South Korea, Hong Kong, Taiwan, Malaysia, Singapore, Japan, Indonesia, Philippines, Cambodia, and others. Guests from Europe such as Finland, Denmark, Italy, Sweden, Germany, and Holland, calculated for more than two million, and the others are 
from America and Oceania. With this number of foreign guests, tourism has made a great contribution and become a spearhead of the country's economic growth. To meet up with the miscellaneous requirements of guests and facilitate the business of tourism and hospitality in the country, it is necessary to improve the quality of services, especially communication in English of the staff who work in the sectors. The teaching of English for Tourism and Hospitality, or the ESP, therefore, needs to emphasise the importance of developing high-level English language communication skills for graduate students. Moreover, the teaching material of this ESP course needs to reflect the communication reality in which the students should have to function. That is the reason why Burns (1998) and Carter and McCarthy (1995), and Wong (2002) have emphasized the value of authentic teaching materials. Schegloff, Koshik, Jacoby, and Olsher (2002) argue that "textbooks using invented dialogue based on intuitions of how certain language functions are accomplished do not always offer students accurate knowledge of language use" (p. 17). Thus, to teach the language appropriately, we must know the language to teach, and the language to be taught must be derived from authentic contexts. The following sections will provide more information about the English language used and taught in the tourism and hospitality industry in Vietnam.

\section{English for specific purposes and the language skills for hospitality students}

English is essential for the work performance of the staff and it facilitates the success of business in tourism and hospitality (Chan, 2002; Hsu, 2014; Prachanant, 2012; Su, 2009). Consequently, "Hospitality English" (Blue \& Harun, 2003, p. 88; Hsu, 2014, p. 51) or "Hotel English" (Shieh, 2012, p. 1730), or the broader term "hospitality language" (Blue \& Harun, 2003, p. 75; Lo \& Sheu, 2008, p. 82) has received greater attention.

Hospitality English is part of broader English for Occupational Purposes (EOP) or English for Vocational Purposes (EVP) courses, which are a branch of English for Specific Purposes (ESP) (Hutchinson \& Waters, 1987, pp. 16-17). ESP is an approach to language teaching and learning in which the content and methodology are determined based on industryspecific needs (Dudley-Evans \& John, 1998; Hutchinson \& Waters, 1987; Johns \& DudleyEvans, 1991).

According to Hutchinson and Waters (1987), ESP is an approach rather than a product, as it does not involve a particular kind of methodology, material or language. All decisions about these matters are made based on "the learner's reason for learning" and it is, therefore, "a learning-centered approach" (built on the principle that language learning is a dynamic and active process in which the learners negotiate in the target language through completion of relevant tasks). It is often referred to as the "language learning process" (Hutchinson \& Waters, 1987, pp. 72-73).

In ESP courses, the central focus is on developing linguistic knowledge and skills related to particular discourses (e.g., tourism and hospitality or chemical engineering) which are characterized by content and skills that the learners will need for their future careers (Basturkmen, 2010, p. 6; Hutchinson \& Waters, 1987, p. 17). In this sense, ESP is different from English for General Purposes (EGP) or General English (GE), which is generally linguistic in its orientation and focuses on developing oral competence, an extensive vocabulary, and the ability to use a wide range of grammatical structures (Basturkmen, 2010). 
The most effective and efficient way of improving the ability of workers to use English in the workplace has been the focus of research which has examined the actual needs of the industry concerning the skills and knowledge required of graduates in ESP courses for hospitality (Chan, 2002; Jasso-Aguilar, 1999; Su, 2009). Proponents in ESP, including Munby (1978) and Hutchinson and Waters (1987), have emphasized the necessity of analyzing learners' needs. Needs analysis, by its nature, is a pragmatic activity that is highly based on localized situations (Schutz \& Derwing, 1981). Based on what the learners have to do or perform through communication in English in the real-life setting, suggestions for change are designed to meet students' needs; course content, teaching methodology, ways of testing and assessment are then designed in response to those needs. In the hotel industry, most of the transactional and interactional activities take place in the form of face-to-face interactions between hotel staff and guests; thus, communication skills, particularly listening and speaking, are essential for the front office (FO) staff who have frequent, direct contact with guests. Communication skills including "soft skills" like the ability to speak clearly, engage in what is said by the speaker, or make the message more explicit (Blue \& Harun, 2003, p. 87), and competence in using English sufficient to communicate with foreign guests is an essential factor in facilitating the financial success of the tourism and hospitality sectors (Hsu, 2014; Shieh, 2012). Consequently, it is vital for universities and colleges which provide training programs in these domains to graduate students who can demonstrate English proficiency. In the context of Vietnam, for that reason, coupled with Government initiatives to improve the English language proficiency of Vietnamese people in general, achieving higher levels of English language competence has been emphasized in the training curricula of educational institutions, particularly in courses serving for the tourism and hospitality sectors.

\section{The course of English for tourism and hospitality in Vietnam}

There are more than 100 universities, colleges and several vocational training centres offering programs for tourism and hospitality in Vietnam (Nguyen \& Chaisawat, 2011, p. 59). For students seeking a hospitality orientation, programs in Hotel Management or Hotel and Restaurant Management are offered. Students who study these programs will ultimately seek employment in the hotel industry, as a manager in a resort or hotel, or as a hotel receptionist.

Within the parameters of the Vietnam Tourism Human Resources Development Project, which was implemented by the Vietnam National Administration of Tourism, in partnership with the European Union (VNAT \& EU, 2009), the Vietnam Tourism Occupational Skills Standards (VTOS) was launched in 2009 as a guide to designing vocational training programs (Ministry of Culture, Sports, \& Tourism, 2012). VTOS constitutes the performance benchmarks for 13 occupations in the tourism and hospitality industries. Apart from the professional skills, English proficiency was a particular focus of the project. Accordingly, a TOEIC English proficiency benchmark was recommended for six specific tourism and hospitality occupations of between 275 and 700, separated into a low and high standard (VNAT \& EU, 2009). For example, a front office worker at a 3-star hotel is required to obtain a TOEIC score of between 475 (low standard) and 650 (high standard). A 2-star hotel may require a lower standard and a 5-star hotel a higher standard. The aim of the TOEIC score was to provide a tool for employers to assess prospective employees' proficiency in English. It also established a benchmark that vocational institutions could use in evaluating and adapting their English training (VNAT \& EU, 2009, p. 17). To achieve these benchmarks, the English language components of hospitality 
courses aim to build students' general English skills, as well as those language skills needed specifically for work in the industry. Course objectives routinely declare that students will be able to demonstrate what they have learned and apply them in real-life contexts; in other words, be able to communicate on common daily topics, perform their work in English, and deal with normal work-related problems.

The English language education in hospitality courses is divided into two stages: General English (GE) and English for Specific Purposes (ESP). The total time allowed for the two stages is between 15 and 18 credits (one credit is 15 credit hours), of which 9 or 12 credits are given to GE and 6 credits are for ESP (MOET, 2008), but this amount of time is normally subject to vary from one institution to another. In GE, students learn foundational English through the four macro skills of listening, speaking, reading and writing. ESP consists of two levels: Basic ESP in which students are introduced to general knowledge about hospitality through language practice in the four macro skills and Advanced ESP, in which students continue to develop and improve their English at a more complex level with a focus on the structures, topics and the skills used in effective communication. By the end of each stage, students are required to take and pass a test ( 5 out of 10 is an average and pass score according to the Vietnamese grade system) which consists of two portions: an oral test in which students are required to present a monologue or a dialogue with their peers on one of the topics discussed and covered in the course, and a written test for integrated skills of listening, reading, writing, vocabulary and language use. Those students who do not obtain an average score on the test have to re-sit the test or re-enroll the course until a satisfactory outcome is achieved.

Textbooks used in ESP courses vary from one institution to another, and they are subject to change. As a general observation (MOET, 2008), ESP courses at both levels often rely entirely on textbooks written by native (L1) speakers of English and published abroad, mainly in L1 countries, for example, England or America. For the ESP stage, 'English for International Tourism' (Dubicka \& O'Keeffe, 2003), 'Tourism 1, 2, 3' (Walker \& Harding, 2007a, 2007b, 2009), 'Going International: English for Tourism' (Harding, 1998), 'Highly Recommended: English for the hotel and catering industry' (Stott \& Revell, 2008), and 'High Season: English for the Hotel and Tourist Industry' (Harding \& Henderson, 1994) are among the textbooks commonly used in Tourism and Hospitality courses. When a textbook such as the one of those listed is adopted, the activities, the language focus, and the practice settings are generally not appropriate to the Vietnamese context as they are not authentically-based and the conversations are mainly spoken by L1 speakers of English (Duong, 2007; Nguyen \& Chaisawat, 2011). Consequently, the activities and the communication practice provided in the textbooks do not address the use of English in an LF setting in which communication occurs mainly among nonnative speakers of English (Vu, 2015).

There are also cases in which the ESP textbooks are compiled by Vietnamese teachers of English from different sources. As a result, the teaching materials of the course are inconsistent in terms of the language focus, the topics, the activities and the tasks designed for practicing communicative skills (Duong, 2007).

\section{Materials evaluation in an ESP course}

Determining course materials and textbooks is a critical component of an ESP course as 
it facilitates the focus on relevant topics and the functions of language needed by learners in their future jobs. However, the selection of the course materials can be challenging, as the course content focuses not only on the needs of the learners and the industry but also on the purposes of the training course. Hutchinson and Waters (1987, p. 96) maintained that there are three possible ways of ensuring the alignment of course design and teaching materials: materials evaluation, materials development, and materials adaptation. Materials or textbook evaluation is an essential activity and it is "basically a matching process: matching needs to available solutions" or "to particular purposes" (Hutchinson \& Waters, 1987, p. 97). Dudley-Evans and John (1998, p. 125) advocated examining the teaching materials based on "how language and skills are used in the target situation." Tomlinson (2003, 2013) maintained that materials evaluation involves making judgments about the effect of the materials on the users (Tomlinson, 2013, p. 21). He also distinguishes between evaluation (subjective - focuses on the users and makes judgments about the material's effects) and analysis (objective - focuses on the materials themselves asking questions about what the materials contain, what they aim to achieve, and what they ask the learners to do) (Tomlinson, 2013, p. 20). Littlejohn (2011) suggested a model that involves three levels of analysis. Level 1 describes the structure, the physical aspects, and the components of the teaching materials. This level addresses the question "what is there" in the teaching material. Level 2 addresses the question "what is required of the learners", focusing on tasks that students are expected to do, by what means, with whom and with what content. Level 3 draws on findings from Levels 1 and 2 to come to some conclusions about the underlying principles of the materials - whether they facilitate language learning and teaching and whether they are appropriate to the target situation. Generally, materials evaluation is a process of reviewing the materials and making judgments to see how the materials match the course objectives or the needs of the users (both teachers who implemented the course and syllabus and the learners who study English for future jobs).

\section{The study and the findings}

\subsection{Research method}

The study aimed to examine the alignment between the ESP course materials and the English language used in the hotel setting in Vietnam. Based on 'the next-turn proof procedure' of conversation analysis (Hutchby \& Wooffitt, 2008, p. 15), 182 natural audio-recording conversations between the front office (FO) staff and foreign guests recorded in the 5 hotels in Vietnam were analyzed for communicative skills and strategies. Content analysis (Berg, 2004) was opted to set limits on the portion of the teaching materials. The course outlines of accessible ESP courses for hospitality, together with two textbooks commonly used in these courses: English for International Tourism (Dubicka \& O'Keeffe, 2003) and High Season: English for the Hotel and Tourist Industry (Harding \& Henderson, 1994) were examined. The course objectives and the course activities derived from the textbooks were the units of analysis. Two key communicative skills were chosen as the units of analysis - speaking and listening skills as these skills are used most frequently in the face-to-face communication between the hotel staff and guests. The analysis of the activities provided for students to practice listening and speaking skills was guided by the framework developed by Littlejohn (2011, p. 198). Three key features of task or activities analysis identified by Littlejohn (2011, p. 191) were guided by three questions: 
(1) What is the student expected to do?

(2) Who with?

(3) With what content?

For question (1), all the activities for listening and speaking skills in the textbooks were coded according to whether the students were expected to practice the skills or subskills that required "scripted responses" (based on the material provided in the book), or whether they had to produce their linguistic expressions or ideas (which was referred to as "initiate") (Littlejohn, 2011, p. 191). Question (2) examined who the students participated with when they completed the task; whether the task was done as the whole class, individually or in pairs and groups. Question (3) focused on the content of the activities, the communicative functions of the language manifested in the activities and the topic areas in which the activities occurred. The audio materials which accompanied the textbooks were a special focus (along with the tapescripts). They were assessed to the length of the recording for listening activities, the complexity of the language, and the accents of the speakers. The course outlines were deidentified using alphabetical coding. For the scope of this article, a brief report on the findings will be presented.

\subsection{Findings and discussion}

From the audios recorded, the English language used in interactions between the Vietnamese hotel FO staff and guests in this study was a lingua franca (ELF) - a medium of communication used by people who do not speak the same first language (Kirkpatrick, 2003), and, as such, shares characteristics with its use in the other environments (Vu, 2015, 2018). To accommodate their English proficiency to that of guests and facilitate the success of the communication, staff used a wide range of communication strategies and skills such as repetition for confirmation, clarification, checking comprehension, highlighting or emphasizing important information, paraphrasing or restating what is heard, using backchannels or asking questions, to make themselves understood and to understand their guests. Negotiation for mutual intelligibility and shared understanding is of utmost importance and it is the goal that the hotel staff and guests aspire to in their communication. FO staff performed various activities and dealt with a wide range of queries from guests, mostly for information, directions to places, or requests for service. The various activities performed by the staff through their communication in English are oriented towards satisfying the guests' diverse needs. Their jobs demand a range of multifunctional language skills (Blue \& Harun, 2003; Prachanant, 2012), and in hotel service settings, these skills need to ensure that not only is communication efficient and adequate, but also "clear, straightforward and candid" (Sparks, 1994, p. 22).

The ESP courses which were analysed in this study were designed to provide students with relevant English, grammar, and communication skills (listening, speaking, reading and writing) so that they will be able to communicate effectively with guests in English once they are employed in a hotel setting. The course objectives examined in the study were quite appropriate to the broad aims of a Hospitality ESP course. Students were given multiple opportunities to listen, speak, write, and read texts in English. All of the objectives were able to be achieved through many activities. The speaking activities appear to address the needs of a typical hotel FO staff member, although, in the natural interactions, more information and 
clarification were needed than was presented in the textbook activities. Listening activities, to a large extent, focused on identifying specific or important information, a function consistent with the nature of the job that staff routinely performs. While the two key skills of speaking and listening were, overall, given emphasis in the textbook activities, they were not the focus of assessment, but just a minor portion was included in the overall assessment of ESP courses. One of the key issues to emerge from the review of the textbooks prescribed for the ESP courses is that almost all the settings for practicing the language in the textbooks are 'foreign' to the lived experiences of the participants in this study, i.e., they are usually situated somewhere in Europe, the UK, America or Australia. In this study, the interaction between the FO staff and guests is mostly focused on local hotel issues, providing advice on where to eat or where to go, or giving information about Vietnamese culture and customs. It is clear that the content of the course, referenced almost exclusively to settings beyond Vietnam, limits students' ability to meet guests' needs.

British English (BrE) or American English (AmE) is the most desired and dominant varieties used in English instruction in Vietnamese educational institutions (Kirkpatrick, 2003). In a real-life context, the hotel staff used English as a lingua franca to communicate with guests from many linguacultural backgrounds, either native speakers of English (NSs) or non-native speakers (NNSs), and most of them were NNSs coming from other Asian countries (VNAT, 2019). The exclusive use of NS accents in the sample conversations from the course materials means that students were not exposed to different accents or varieties of non-native English. Given that, in the workplace, staff will often communicate in English with NNSs rather than NSs, this limits the development of students' aural sensitivity and must, in consequence, impede their understanding of the conversation of the range of guests who come from different linguacultural backgrounds as described above. The scripted conversations examined in the textbooks and the CDs seemed simple and the speakers in these conversations generally had no trouble when interacting with one another. During the natural interactions between the staff and guests, some flexibility was required to deal with contingencies and unexpected happenings, and more importantly, communicative skills and strategies were employed to facilitate the success of communication. In the textbooks, conversations were delivered in sequential order of questions-answers and there were few strategies for negotiating meaning between speakers. The language used in the textbooks was simple (e.g., "go straight on"; "turn right/left"; etc.) and was inadequate to meet the face-to-face communication demands that staff faced when responding to guests' various requests and queries which are, by comparison, more complex and extended (e.g., "keep going straight down that way, ... go to the big roundabout here, /and you'll see on the right...). Although the ESP courses for hospitality aim to make students understand English spoken in clear standard speech, it is clearly not designed to expose students to the English varieties to which they will be typically exposed in a hotel work environment.

\section{Conclusion and implications for the teaching of ESP for hospitality students}

The textbooks reviewed in this study reveal a mismatch in the way in which English is practiced by students during their training and the way is it used by staff in the FO. Although the textbooks provide a range of activities for practicing the communicative skills of speaking and listening, they do not provide opportunities for students to gain experience of working with English as a lingua franca or to identify and practice the strategies that can ensure effective 
communication with guests. The practice settings for speaking and listening practice were not relevant, nor were the materials culturally appropriate as they were not familiar with students. In addition, the exclusive use of NS accents in conversations means that different accents or varieties of non-native English were excluded. During the course, students were not exposed to any other English-speaking environment besides those presented by the teacher (who is normally Vietnamese and, therefore an NNS of English) or through the audio materials. In the workplace, staff often communicate in English with NNSs rather than NSs. It is, therefore, necessary for hospitality students to be exposed to different varieties of English. Students would benefit from more practice situations that are contextualized and include authentic scenarios which can be achieved through experiential learning (practicum or workplace learning) in the hotel industry. Opportunities within courses for practicing listening and speaking - the two most frequently used skills in face-to-face interactions - should be increased. These skills need to be focused and strategies for negotiation of meaning, including checking for understanding, requesting clarification and confirmation that need to be emphasized in English courses as these skills are important for successful communication in ELF. In addition, the teaching of English for communication in a multilingual environment like the one in this study would recognize the new social reality. Rather than focusing on acquiring the standard forms of native-like proficiency, the focus should be on the ability to use language successfully in a lingua franca context. Thus, students in ESP courses for Hospitality should have to develop this competence if they are to be in the position to respond to the diversity in guests' linguacultural backgrounds and to the varieties of English they use.

\section{References}

Academy of Managers for Construction and Cities. (2018). Tầm nhì đô thị thông minh tại Việt Nam [Smart urban's vision in Vietnam]. Retrieved March 25, 2018, from http://amc.edu.vn/vi/tin-tuc-su-kien/tin-xay-dung-va-do-thi/khoa-hoc-cong-nghe-moitruong/7136-tam-nhin-do-thi-thong-minh-tai-viet-nam.html

Basturkmen, H. (2010). Developing courses in English for specific purposes. New York, NY: Palgrave Macmillan.

Berg, B. L. (2004). Qualitative research methods for the social sciences (5th ed.). Boston, MA: Allyn and Bacon.

Blue, G. M., \& Harun, M. (2003). Hospitality language as a professional skill. English for Specific Purposes, 22 (1), 73-91. doi:10.1016/s0889-4906(01)00031-x

Burns, A. (1998). Teaching speaking. Annual Review of Applied Linguistics, 18, 102-123. doi:10.1017/S0267190500003500

Carter, R., \& McCarthy, M. (1995). Grammar and the spoken language. Applied Linguistics, 16 (2), 141-158. doi:10.1093/applin/16.2.141

Chan, M. Y. (2002). English language communication training needs of front office assistants of hotels in Kuala Lumpur. In J. Mukundan, A. A. Samad \& T. C. Seng (Eds.), Readings in English language teaching (ELT): Selected papers from the millennium MICELT (pp. 35-44). Serdang, Malaysia: Penerbit Universiti Putra Malaysia. 
Dubicka, I., \& O’Keeffe, M. (2003). English for international tourism pre-intermediate. London, UK: Pearson Elt.

Dudley-Evans, T., \& John, M. J. S. (1998). Developments in English for specific purposes: A multi-disciplinary approach. Cambridge, UK: Cambridge University Press.

Duong, T. H. O. (2007). Meeting students' needs in two EAP programmes in Vietnam and New Zealand: A comparative study. RELC Journal: A Journal of Language Teaching and Research, 38 (3), 324-349. doi:10.1177/0033688207085850

Gunnarsson, B. L. (2009). Professional discourse. London, UK: Continuum International Publishing Group.

Harding, K. (1998). Going international: Student's book: English for tourism. Oxford, UK: Open University Press.

Harding, K., \& Henderson, P. (1994). High season: English for the hotel and tourist industry. Oxford, UK: Oxford University Press.

Hsu, L. (2014). Effectiveness of English for specific purposes courses for non-English speaking students of hospitality and tourism: A latent growth curve analysis. Journal of Hospitality, Leisure, Sport \& Tourism Education, 15, 50-57. doi:10.1016/j.jhlste.2014.05.001

Hutchby, I., \& Wooffitt, R. (2008). Conversation analysis. Cambridge, UK: Polity Press.

Hutchinson, T., \& Waters, A. (1987). English for specific purposes: A learner-centered approach. Cambridge, UK: Cambridge University Press.

Jasso-Aguilar, R. (1999). Sources, methods and triangulation in needs analysis: A critical perspective in a case study of Waikiki hotel maids. English for Specific Purposes, 18 (1), 27-46. doi:10.1016/S0889-4906(97)00048-3

Johns, A. M., \& Dudley-Evans, T. (1991). English for specific purposes: International in scope, specific in purpose. TESOL Quarterly, 25 (2), 297-314.

Kirkpatrick, A. (2003). English as an ASEAN lingua franca: Implications for research and language teaching. Asian Englishes, 6 (2), 82-91.

Littlejohn, A. (2011). The analysis of language teaching materials: Inside the Trojan Horse. In B. Tomlinson (Ed.), Materials development in language teaching. Cambridge, UK: Cambridge University Press.

Lo, Y., \& Sheu, C. (2008). The design, implementation, and evaluation of an English tour guide project. The Asian ESP Journal, 4 (2), 79-95.

Ministry of Culture, Sports, \& Tourism. (2012). Vietnam tourism occupational skills standards. Retrieved October 19, 2015, from: http://bvhttdl.gov.vn/vn/nghiencuu-traodoi/pho-bientai-lieu-va-video-huong-dan-13-tieu-chuan-nghe-du-lich-viet-nam-vtos.html

MOET. (2008). Report on teaching and learning English in non-English major universities. Paper presented at The Teaching \& Learning English in Non-English Major Universities, Hanoi.

Munby, J. (1978). Communicative syllabus design: A sociolinguistic model for defining the content of purpose-specific language programmes. Cambridge, UK: Cambridge University Press. 
Nguyen, H., \& Chaisawat, M. (2011). The current situation and future development of hospitality and tourism higher education in Vietnam. Tourism, Hospitality and Culinary Arts, 3 (2), 57-67.

Prachanant, N. (2012). Needs analysis on English language use in tourism industry. Procedia Social and Behavioral Sciences, 66, 117-125. doi:10.1016/j.sbspro.2012.11.253

Schegloff, E. A., Koshik, I., Jacoby, S., \& Olsher, D. (2002). Conversation analysis and applied linguistics. Annual Review of Applied Linguistics, 22, 3-31. doi:10.1017/S0267190502000016

Schutz, N., \& Derwing, B. (1981). The problem of need assessment in English for Specific Purposes: Some theoretical and practical considerations. In R. MacKay \& J. D. Palmer (Eds.), Languages for Specific Purposes (pp. 29-44). Rowley, MA: Newbury House.

Shieh, W. (2012). Hotel employees' perception on their workplace English use: An example from Taiwan. US-China Foreign Language, 10 (11), 1729-1733.

Sparks, B. (1994). Communicative aspects of the service encounter. Journal of Hospitality \& Tourism Research, 17 (2), 39-50. doi:10.1177/109634809401700205

Stott, T., \& Revell, R. (2008). Highly recommended: English for the hotel and catering industry. Oxford, UK: Oxford University Press.

Su, S.-W. (2009). Designing and delivering an English for hospitality syllabus: A Taiwanese case study. RELC Journal, 40 (3), 280-313. doi:10.1177/0033688209343845

Tomlinson, B. (2003). Developing materials for language teaching. London, UK: Continuum.

Tomlinson, B. (2013). Developing materials for language teaching. London, UK: Bloomsbury Publishing.

Tse, T. S. M. (2010). What do hospitality students find important about internships? Journal of Teaching in Travel and Tourism, 10 (3), 251-264. doi:10.1080/15313221003792027

VNAT., \& EU. (2009). Curriculum guidelines for English training in tourism vocational training in Vietnam: Vietnam human resources development in Tourism project. Hanoi.

VNAT. (2019). International visitors to Vietnam in December and 12 months of 2018. $\begin{array}{llll}\text { Retrieved } \quad \text { September 20, from } & \text { 2019, }\end{array}$ http://vietnamtourism.grov.vn/english/index.php/items/13551

Vu, T. H. V. (2015). English as a lingua franca in the Vietnamese hotel industry: Communicative strategies and their implications for vocational education (Doctoral dissertation, Curtin University, Singapore).

Vu, T. H. V. (2018). ELF in the Vietnamese hotel: Strategies for facilitating communication between staff and guests. Proceedings of the International Conference on English Language Teaching 2018. ELT for Innovation and Integration, 414-427.

Walker, R., \& Harding, K. (2007a). Tourism 1: Provision (1st ed.). Oxford, UK: Oxford University Press.

Walker, R., \& Harding, K. (2007b). Tourism 2: Encounters (1st ed.). Oxford, UK: Oxford University Press. 
Walker, R., \& Harding, K. (2009). Tourism 3: Management (1st ed.). Oxford, UK: Oxford University Press.

Wong, J. (2002). “Applying” conversation analysis in applied linguistics: Evaluating dialogue in English as a second language textbooks. International Review of Applied Linguistics, 40 (1), 37-60. 